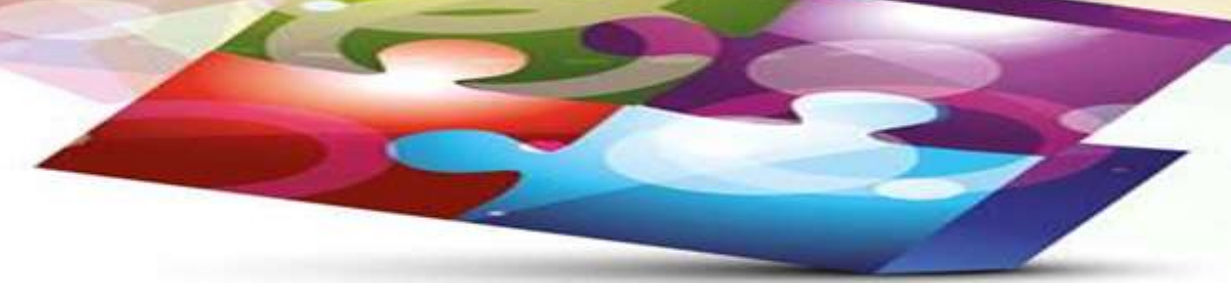

\title{
POLÍTICAS EDUCACIONAIS PARA FORMAÇÃO CONTINUADA DE DIRETORAS ESCOLARES DO MUNICÍPIO DE REGENTE FEIJÓ-SP
}

\section{EDUCATIONAL POLICIES FOR CONTINUING TRAINING OF SCHOOL DIRECTORS IN THE MUNICIPALITY OF REGENTE FEIJÓ-SP}

\author{
Josenildo de JESUS ${ }^{1}$ \\ Cristiano Amaral Garboggini DI GIORGI ${ }^{2}$ \\ Marcos Vinicius FRANCISCO ${ }^{3}$
}

\begin{abstract}
Resumo: Esta pesquisa foi desenvolvida no município de Regente Feijó-SP tendo como objeto de estudo as Políticas Educacionais para formação continuada de diretoras escolares. O objetivo foi analisar em que medida as atividades de formação continuada, oferecidas às gestoras do município, corresponderam às suas necessidades formativas. Neste estudo, de abordagem qualitativa descritivo-explicativa, foram realizadas entrevistas semiestruturadas com sete diretoras (permaneceram mais tempo na função, no período de 2009 a 2018). As transcrições foram problematizadas por meio do diálogo com literaturas que tenham interface ou assumam o materialismo histórico-dialético como base. O estudo demonstrou que o município de Regente Feijó realizou políticas de formação para as diretoras, mas que prevaleceu um caráter fragmentado de ações e a quase inexistência de consulta às gestoras sobre suas necessidades formativas. Ainda assim, elas valorizaram a formação, numa constante luta por melhoria das condições de trabalho.
\end{abstract}

Palavras chave: Gestão Escolar; Formação Continuada; Política Educacional.

Abstract: This research was developed in the Regente Feijó-SP city, having as object of study the Educational Policies for the continuous formation of school principals. The objective was

\footnotetext{
1 Universidade do Oeste Paulista (Unoeste)/Mestre em Educação pelo Programa de Pós-Graduação em Educação.

2 Universidade do Oeste Paulista (Unoeste)/Programa de Pós-Graduação em Educação.

${ }^{3}$ Universidade Estadual de Maringá (UEM)/Departamento de Ciências do Movimento Humano e Programa de Pós-Graduação em Educação; Universidade do Oeste Paulista (Unoeste)/Programa de Pós-Graduação em Educação.
}

JESUS, Josenildo de. DI GIORGI, Cristiano Amaral Garboggini. FRANCISCO, Marcos Vinicius. Políticas educacionais para formação continuada de diretoras escolares do município de Regente Feijó-SP Horizontes - Revista de Educação, Dourados-MS, v. 9, n. 41, 2020. Faculdade de Educação (FAED) Universidade Federal da Grande Dourados (UFGD) DOI 10.30612/hre.v9i16.12973 


\section{MORIZONTES - REVISTA DE EDUCAÇÃOO}

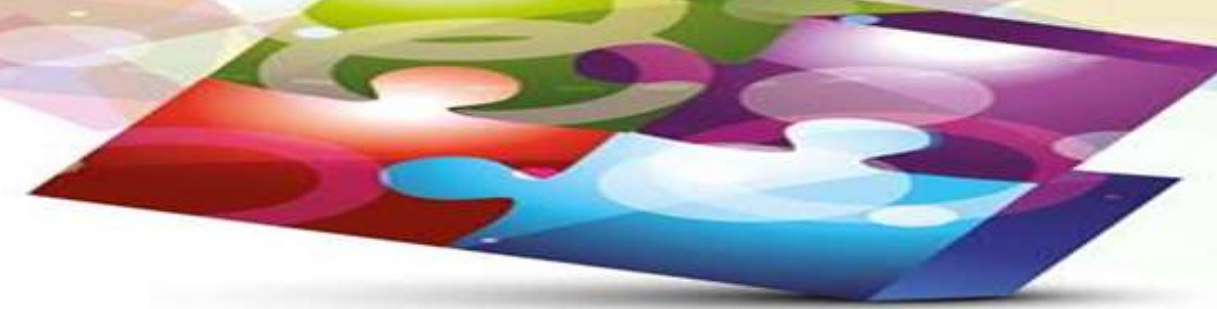

to analyze the extent to which the continuing education activities, offered to city managers, corresponded to their training needs. In this study, with a qualitative descriptive-explanatory approach, semi-structured interviews were conducted with seven directors (they remained in the function longer, from 2009 to 2018). The transcriptions were problematized through dialogue with literatures that have an interface or take historical-dialectical materialism as a basis. The study showed that the municipality of Regente Feijó carried out training policies for the directors, but that a fragmented character of actions and the almost inexistence of consultation with managers about their training needs prevailed. Even so, they valued training, in a constant struggle to improve working conditions.

Keywords: school management; continuing education; educational policy.

\section{INTRODUÇÃO}

É importante destacar que, no Brasil, são adotados vários tipos de políticas para selecionar os/as diretores/as escolares, desde as organizadas por programas do Ministério da Educação (MEC), como algumas produzidas pelos municípios ou estados (CRUZETTA; SOUZA, 2020). Porém, independente do tipo, nas últimas décadas, conforme Parente (2017, p. 256) “a inserção dos preceitos gerencialistas na gestão pública brasileira tem se efetivado por meio de políticas públicas centradas no racionalismo e na produtividade”. Tais medidas estão cada vez mais alinhadas às necessidades do mercado, com forte presença das parcerias públicoprivadas, e um posicionamento regulador por parte do Estado, que deixa de ser provedor. Assim, os/as gestores/as assumem um papel técnico e racional, ao controlar as ações e monitorar o desempenho das escolas, muito presos à lógica de avaliações padronizadas.

De acordo com Paro (2010), há três modos de escolha de diretores escolares para atender às políticas de gestão educacional municipal ou estadual: a nomeação, o concurso público e a

JESUS, Josenildo de. DI GIORGI, Cristiano Amaral Garboggini. FRANCISCO, Marcos Vinicius. Políticas educacionais para formação continuada de diretoras escolares do município de Regente Feijó-SP Horizontes - Revista de Educação, Dourados-MS, v. 9, n. 41, 2020. 


\section{MORIZONTES - REVISTA DE EDUCAÇÃOO}

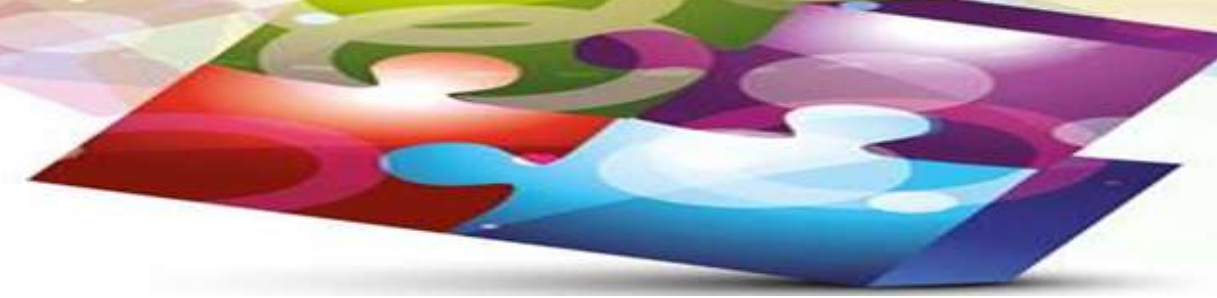

eleição pela comunidade. Na rede municipal de Regente Feijó-SP, foco desta pesquisa, o critério é a nomeação.

Nessa perspectiva, Paro (1999) destaca que a nomeação é feita por critério político pelo Secretário de Educação, ou seja, o chefe do Poder Executivo, que escolhe a pessoa de sua confiança para ocupar o cargo proposto. Não é vista como uma alternativa adequada, pois por se tratar de um cargo político, visa atender ao clientelismo do partido, de modo que o candidato não é escolhido por sua competência, experiência e conhecimento na gestão da educação, mas por afinidade ao partido (PARO, 1999; CRUZETTA; SOUZA, 2020).

Geralmente, a prerrogativa para esse ato é a argumentação de que a lei garante a escolha de seus representantes. No entanto, muitos/as diretores/as não correspondem à gestão das escolas, mas aos interesses dos grupos privados aos quais estão submetidos.

Paro (1999) ressalta que a indicação política de um/a dirigente escolar pressupõe que a direção da escola funcione como um cargo político de confiança do governante municipal ou estadual, como um meio de compensação no jogo eleitoral. Para o mesmo autor, a abrangência do concurso público como critério para a seleção dos/as administradores/as escolares implica o entendimento da direção escolar como um cargo técnico, cujo ocupante o exercerá permanentemente.

Na concepção de Paro (1998), a escolha do/a diretor/a escolar, por meio de concurso de provas e títulos, se assenta nos seguintes pressupostos: trata-se de um processo imparcial que visa tão somente uma seleção técnica, não favorece ninguém, apenas seleciona de maneira objetiva aqueles que têm os conhecimentos exigidos. Porém, não é garantia de que será um/a bom/boa gestor/a, apesar do caráter alegadamente democrático, tendo em vista que, ao 


\section{MORIZONTES - REVISTA DE EDUCAÇÃOO}

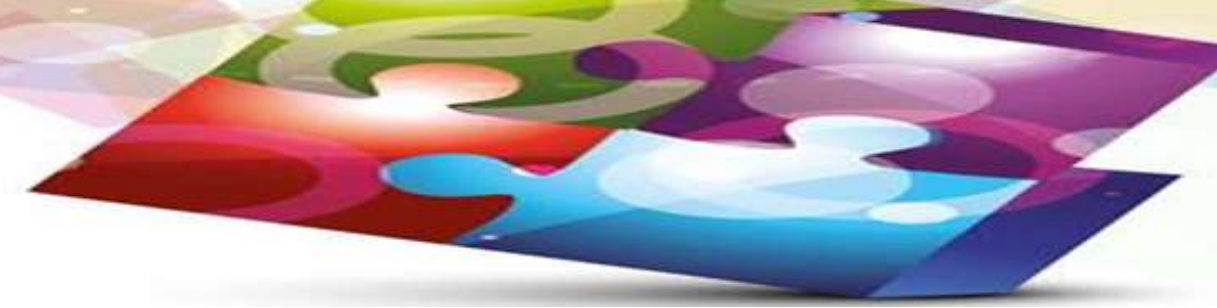

reconhecer que o/a aprovado/a ao cargo de diretor/a selecione a escola, não proporciona a mesma prática democrática aos trabalhadores da escola, ou seja, a liberdade para escolherem os/as seus/suas diretores/as.

Essa forma de concurso para gestor escolar é muito comum no estado de São Paulo. A prática da realização de concurso inibe algumas atividades políticas nas instituições públicas; entretanto, uma das alternativas com menos vícios que as outras opções é a eleição, que melhor contribui para a democratização dos processos educacionais (PARO, 1998).

Mediante tais aspectos, a problemática assumida nesta investigação foi: Quais os processos formativos oferecidos às diretoras de escolas de Regente Feijó-SP e em que medida os projetos de formação continuada oferecidos correspondem às suas necessidades formativas e como refletem em sua prática?

Conforme Di Giorgi et al. (2011), o levantamento das necessidades formativas de professores/as e gestores/as é importante, uma vez que possibilita atender às suas expectativas, pautadas em suas vivências no cotidiano escolar, onde desenvolvem a prática educacional. A análise de necessidades formativas vem sendo utilizada como instrumento de planejamento das ações educacionais desde o final da década de 1960. Por meio desta, pode-se auxiliar a estruturação e a organização de processos formativos, respondendo com mais eficácia às exigências sociais e políticas (DI GIORGI et al., 2011). Nesta pesquisa, parte-se da premissa de que, por meio do levantamento das necessidades formativas, haverá maior clareza da aplicabilidade das políticas educacionais, fornecendo informações para a definição de conteúdos e atividades formativas dos/as gestores/as escolares.

JESUS, Josenildo de. DI GIORGI, Cristiano Amaral Garboggini. FRANCISCO, Marcos Vinicius. Políticas educacionais para formação continuada de diretoras escolares do município de Regente Feijó-SP Horizontes - Revista de Educação, Dourados-MS, v. 9, n. 41, 2020. 


\section{MORIZONTES - REVISTA DE EDUCAÇÃOO}

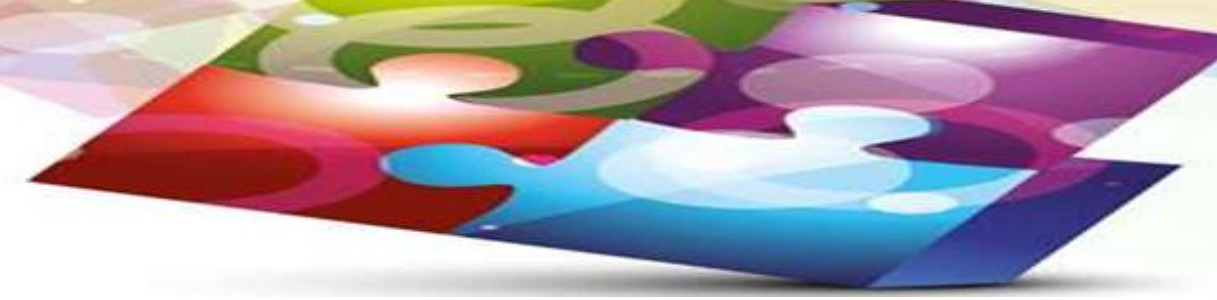

A escola atual tem vivenciado grandes transformações culturais, que atravessam ordens econômicas, políticas, culturais e atingem os mais diversos sujeitos (OLIVEIRA, 2008). As questões que permeiam a gestão escolar são de muitas ordens, no entanto, as formações calcadas nos conhecimentos práticos de gestão humana, pedagógica e social diferenciam o trabalho na instituição de ensino. Sua legalidade, fundamentada no diálogo e articulação moral no que concerne aos processos decisórios de escolha e de ação, é fator de mudança numa perspectiva democrática (PARO, 1998, 1999, 2010; OLIVEIRA, 2008; PARENTE, 2017).

Para Libâneo (2013), torna-se imprescindível um ambiente adequado, que facilite a integração da cultura favorável às mudanças e participação da equipe escolar. Jesus (2004) destaca a formação continuada ou contínua como uma oportunidade para o trabalho em equipe: a cooperação deve ser orientada para a resolução de problemas comuns para além do acréscimo de capacidades profissionais, em conformidade com os objetivos de cada ação.

Diante de tais aspectos, assumiu-se como objetivo geral deste estudo: analisar em que medida as atividades de formação continuada, oferecidas aos/as gestores/as do município de Regente Feijó-SP, correspondem às suas necessidades formativas.

\section{DELINEAMENTO METODOLÓGICO}

Esta investigação de natureza qualitativa descritivo-explicativa foi desenvolvida na rede educacional do município de Regente Feijó, cidade do interior de São Paulo, com aproximadamente, 20.394 habitantes (IBGE, 2020). O município de Regente Feijó ofereceu campo para pesquisa, sobretudo a partir de ações já desenvolvidas pelos pesquisadores, visto

JESUS, Josenildo de. DI GIORGI, Cristiano Amaral Garboggini. FRANCISCO, Marcos Vinicius. Políticas educacionais para formação continuada de diretoras escolares do município de Regente Feijó-SP Horizontes - Revista de Educação, Dourados-MS, v. 9, n. 41, 2020. 


\section{HORIZONTES - REVISTA DE EDUCAÇÃO}

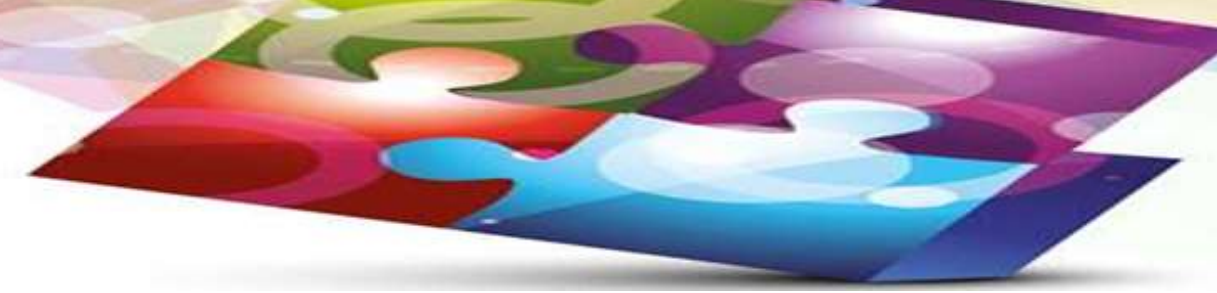

que comporta um ambiente propício à averiguação de políticas educacionais de formação de diretores/as escolares.

\section{Procedimentos de coleta e análise dos dados}

Adotou-se como procedimento metodológico a realização de entrevistas semiestruturadas com sete diretoras, as mais antigas ocupando tais cargos (2009-2018). O roteiro de entrevista foi construído, tendo como base o levantamento das políticas educacionais de formação das diretoras, estruturadas e executadas pelo município. Para Triviños (1987, p. 146), as entrevistas semiestruturas partem "de certos questionamentos básicos, apoiados em teorias e hipóteses, que interessam à pesquisa, e que, em seguida, oferecem amplo campo de interrogativas, fruto de novas hipóteses que vão surgindo" conforme o diálogo estabelecido entre pesquisador/a e participante.

Em linhas gerais, as entrevistas objetivaram identificar se período supracitado participaram de algum processo formativo (federal, estadual, municipal, privado ou promovido por Organização Não Governamental - ONG); se foram consultadas previamente sobre suas necessidades de formação; se em alguma atividade formativa que participaram, houve, durante o processo, consulta de suas necessidades; e se as formações corresponderam às expectativas de uma gestão democrática. As entrevistas foram gravadas e, posteriormente, transcritas e tiveram duração de aproximadamente 40 minutos.

A análise foi subsidiada pela descrição e posterior problematização dos dados a partir de referenciais teóricos que interseccionam ou assumam como escopo o materialismo históricodialético, já que se pretendeu realizar uma leitura do assunto mediante as influências dos 


\section{HORIZONTES - REVISTA DE EDUCAÇÃO}

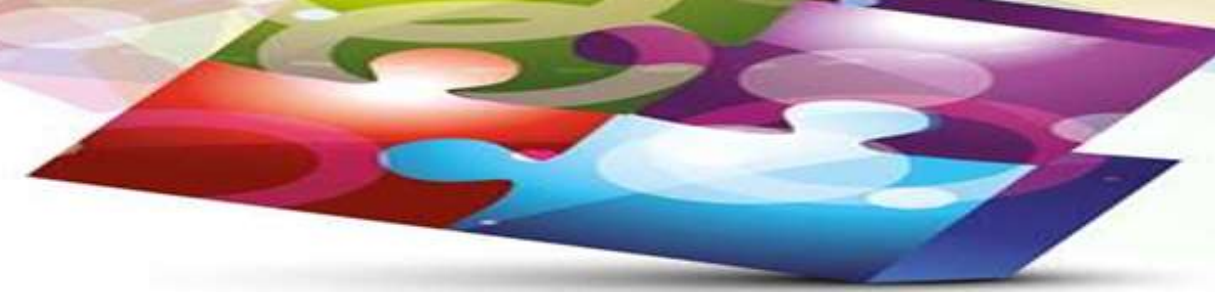

determinantes históricos, sociais e político-econômicos (PAULO NETTO, 2011; EVANGELISTA; SHIROMA, 2019). Essa preocupação também foi expressa por Baczinski e Comar (2019) ao reconhecerem que nessa perspectiva teórica problematizam-se os dados de pesquisas, bem como as ações educativas, reconhecendo as possibilidades efetivas para se construir uma educação que ultrapasse a lógica do mercado, materializada na Nova Gestão Pública neoliberal.

\section{Procedimentos éticos}

A pesquisa foi aprovada pelo Comitê de Ética em Pesquisa da Universidade do Oeste Paulista. Foram assegurados todos os cuidados necessários na condução da pesquisa com seres humanos, desde o uso de Termos de Consentimento Livre Esclarecidos (TCLE), bem como da não identificação dos nomes das escolas e sigilo das participantes.

\section{ANÁLISE E DISCUSSÃO DOS DADOS}

Ao analisar o processo de participação das diretoras em processos formativos, identificaram-se, apenas, ações ofertadas pela própria Secretaria Municipal de Educação, conforme o Quadro 01, exceção a uma única gestora que mencionou ter participado de uma formação ofertada pelo estado de São Paulo:

JESUS, Josenildo de. DI GIORGI, Cristiano Amaral Garboggini. FRANCISCO, Marcos Vinicius. Políticas educacionais para formação continuada de diretoras escolares do município de Regente Feijó-SP Horizontes - Revista de Educação, Dourados-MS, v. 9, n. 41, 2020. Faculdade de Educação (FAED) Universidade Federal da Grande Dourados (UFGD) 


\section{MORIZONTES - REVISTA DE EDUCAÇÃO}

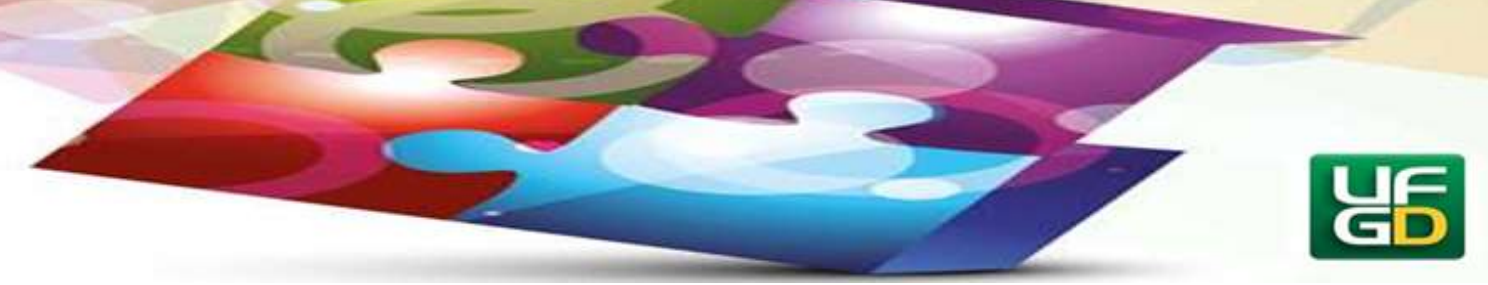

Quadro 01 - Participação das diretoras em processos formativos 2009-2018

\begin{tabular}{|l|l|}
\hline Participantes & \multicolumn{1}{c|}{ Respostas } \\
\hline Diretora 1 & Sim, sempre estamos em constante formação. \\
\hline Diretora 2 & Sim, de palestras, mas não de formação específica. \\
\hline Diretora 3 & Sim, participei de cursos de gestão escolar. \\
\hline Diretora 4 & Sim, de cursos de gestão escolar. \\
\hline Diretora 5 & $\begin{array}{l}\text { Sim, participei de algumas palestras, porém formação } \\
\text { específica não. }\end{array}$ \\
\hline Diretora 6 & Sim, participei. \\
\hline Diretora 7 & Sim, participei de palestras, mas não de cursos de \\
& gestão. \\
\hline
\end{tabular}

Fonte: Pesquisa de Campo (2019-2020)

Considerando as respostas das participantes, foi possível identificar que todas responderam sim, ao se referirem às formações e/ou ações desenvolvidas pelo município. Todavia, nas falas manifestadas, percebeu-se certa inquietação, uma vez que, algumas haviam participado de cursos, enquanto outras tinham assistido, apenas, palestras (diretoras 2, 5, 7), porém não de formações específicas. Já as respostas dadas pelas gestoras $(1,3,4,6)$ referem-se ao envolvimento em de cursos de formação de gestores/as.

Tais dados são preocupantes, sobretudo quando há para algumas delas apenas a menção de cursos rápidos ou descontextualizados a situação vivida, aspectos revelados no aprofundamento das respostas inicialmente dadas pelas participantes. Marin (1995) já salientava em meados dos anos de 1990, que cursos esporádicos e palestras dificilmente contribuem com o efetivo processo de formação continuada, uma vez que abordam superficialmente questões que, muitas vezes, não possuem ligações estreitas com os contextos 


\section{HORIZONTES - REVISTA DE EDUCAÇÃO}

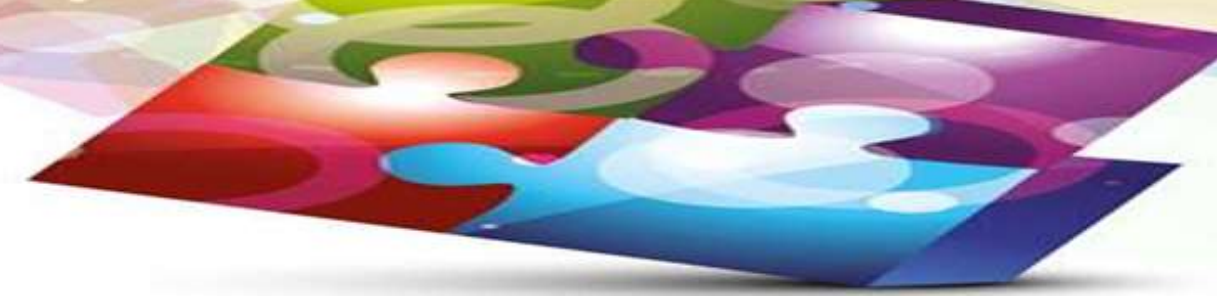

de atuação profissional. Viotto Filho e Ponce (2015) salientam que com relação à apropriação e objetivação de conhecimentos e saberes acerca do exercício profissional, as escolas deveriam funcionar como lócus de formação e contato com os conhecimentos científicos, filosóficos e artísticos. Posto isso, os processos formativos devem atender a trajetória daqueles/as que exercem sua profissão em determinados contextos histórico-sociopolíticos.

Nessa perspectiva, oportunos são os apontamentos de Baczinski e Comar (2019), ao reforçarem uma dimensão que se entende ser fundamental nos processos formativos. No caso deste artigo, estendemos tais apontamentos, para a formação de gestores/as.

É desse cenário que reiteramos a importância da reflexão em torno do papel da educação escolar. Isso instiga tanto uma reflexão acerca do trabalho historicamente realizado por tal instituição, quanto em relação ao papel social que ela potencialmente tem condições de exercer com vistas à superação das desigualdades. Claro, sabemos que a escola sozinha não muda a sociedade, mas ela é peça central na formação da consciência e releitura do empírico que insiste em naturalizar as injustiças, especialmente no campo educacional. (BACZINSKI; COMAR, 2019, p. 84).

Corroboram tais posicionamentos, Parente (2017, p. 265), já que “a construção do modelo de organização da escola é regida, portanto, pelo embasamento teórico-conceitual disponibilizado por meio de estudos e pesquisas realizados no meio acadêmico, vivenciados pelos gestores mediante formação específica e sintonia estabelecida entre" os/as diretores/as e a Secretaria de Educação, em que se encontram diretamente vinculados/as, posto que ambos/as, “em regime de colaboração, deveriam planejar o formato de organização da escola".

JESUS, Josenildo de. DI GIORGI, Cristiano Amaral Garboggini. FRANCISCO, Marcos Vinicius. Políticas educacionais para formação continuada de diretoras escolares do município de Regente Feijó-SP Horizontes - Revista de Educação, Dourados-MS, v. 9, n. 41, 2020. Faculdade de Educação (FAED) Universidade Federal da Grande Dourados (UFGD) 


\section{MORIZONTES - REVISTA DE EDUCAÇÃO}

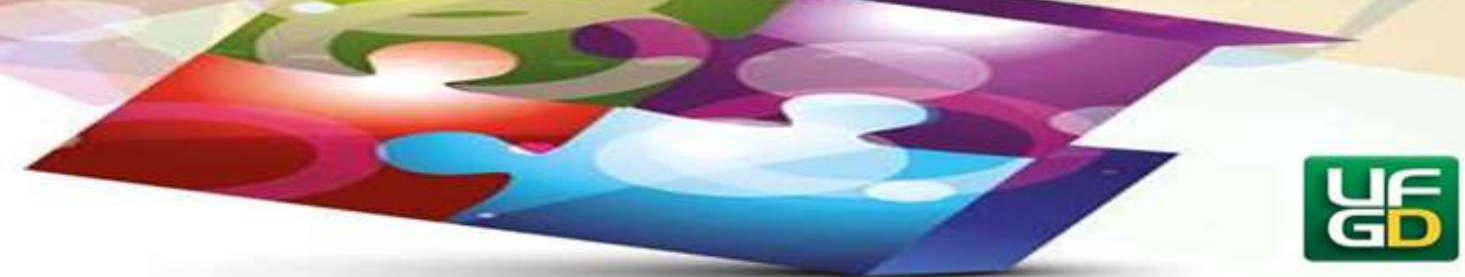

Barreiro e Moura (2010, p. 112) defendem, a partir de investigações realizadas, que a “formação de gestores, por meio de programas de formação continuada, representa a expressão de mudanças mais amplas na sociedade, que aliadas à aprovação da legislação educacional vão impulsionar reformas na educação, e em particular na gestão escolar”

Outro aspecto a salientar, embora pareça óbvio, refere-se à ausência de formações, em nível federal, expressando a necessidade de criação de um Sistema Nacional de Educação. Em entrevista concedida ao pesquisador Newton Duarte, Demerval Saviani reforçou a necessidade de termos um Sistema Nacional de Educação, esse entendido como "um conjunto unificado que articula todos os aspectos da educação no país inteiro, com normas comuns válidas para todo o território nacional e com procedimentos também comuns visando a assegurar educação com o mesmo padrão de qualidade a toda a população do país”. (DUARTE; SAVIANI, 2019, p. 6).

Questionadas a respeito dos processos formativos recebidos e se houve alguma consulta prévia de suas necessidades de atuação profissional (Quadro 02), as participantes 2, 3, 4, 5 e 7 responderam que, não houve, ou não se lembravam de alguma consulta acerca de suas necessidades formativas. A exceção ficou por conta das respostas das participantes 1 e 6 .

Quadro 02 - Necessidades formativas X formações recebidas

\begin{tabular}{|c|l|}
\hline Participantes & \multicolumn{1}{c|}{ Respostas } \\
\hline Diretora 1 & $\begin{array}{l}\text { [..] os cursos são oferecidos, recebemos até ofertas por telefone, mas eu } \\
\text { priorizo as formações presenciais oferecidas pelo município. [...] Sempre } \\
\text { tem algo direcionado: a gente tem noção da necessidade, e o que é } \\
\text { oferecido é o que estamos precisando. }\end{array}$ \\
\hline Diretora 2 & Não houve. \\
\hline Diretora 3 & $\begin{array}{l}\text { Não, geralmente eles vêm com a formação pronta. Não há levantamento } \\
\text { feito antes [...] }\end{array}$ \\
\hline
\end{tabular}

JESUS, Josenildo de. DI GIORGI, Cristiano Amaral Garboggini. FRANCISCO, Marcos Vinicius. Políticas educacionais para formação continuada de diretoras escolares do município de Regente Feijó-SP Horizontes - Revista de Educação, Dourados-MS, v. 9, n. 41, 2020. Faculdade de Educação (FAED) Universidade Federal da Grande Dourados (UFGD) 


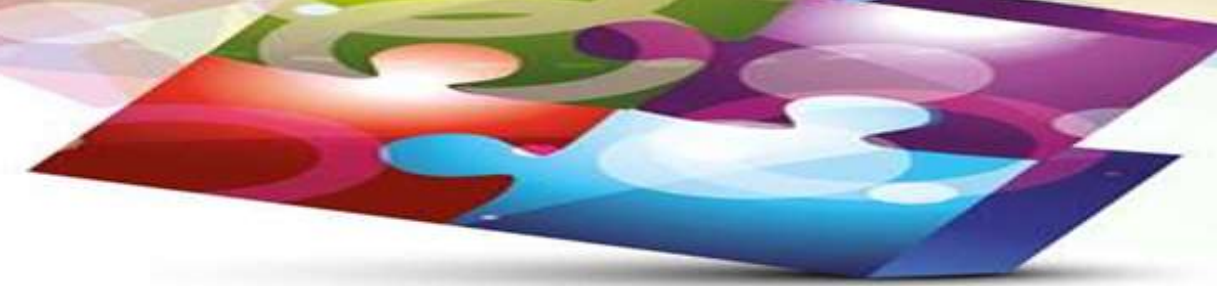

\begin{tabular}{|l|l|}
\hline Diretora 4 & $\begin{array}{l}\text { Não, as coisas são discutidas nas reuniões, onde são colocadas as } \\
\text { dificuldades e esclarecimentos. }\end{array}$ \\
\hline Diretora 5 & Não, não houve. \\
\hline Diretora 6 & Sim. \\
\hline Diretora 7 & $\begin{array}{l}\text { Não perguntam, as formações não são a partir de nossas necessidades. } \\
\text { Ainda não, espero que tenha algo mais focado, pois é o que muitos } \\
\text { diretores precisam. Às vezes a gente é nomeada para o cargo e não tem } \\
\text { nenhuma formação, só algumas dicas e leis, mas necessita de formação } \\
\text { prática mesmo. }\end{array}$ \\
\hline
\end{tabular}

Fonte: Pesquisa de Campo (2019-2020)

Ou seja, embora não haja consenso nas falas das participantes, é oportuno problematizar que a ausência de formações a partir das necessidades das diretoras, contraria os princípios que fundamentam à gestão democrática.

Nesse sentido, destacamos que a gestão democrática na política pública é, sobretudo, formativa, pois, especificamente na educação, implica: mediação de conflitos; escuta de projetos opositores; esforço tensionante para formulação de antítese e síntese; possibilidade de lidar com escolhas equivocadas, ainda que coletivas, para aprender com os próprios erros. Significa, cotidianamente, fazer o enfrentamento dos dilemas advindos de um processo que se dá em meio a concepções e projetos societários diversos, sensibilizados para a ideia de que as chances sejam constitutivas dos próprios dilemas (POLI; LAGARES, 2017, p. 845).

Quando não chamadas para o diálogo, a partir de suas necessidades formativas, as diretoras assumem "um papel meramente burocrático" de executoras "de tarefas" ou de formações recebidas que, na maioria dos casos estão sempre atreladas à lógica gerencial,

JESUS, Josenildo de. DI GIORGI, Cristiano Amaral Garboggini. FRANCISCO, Marcos Vinicius. Políticas educacionais para formação continuada de diretoras escolares do município de Regente Feijó-SP Horizontes - Revista de Educação, Dourados-MS, v. 9, n. 41, 2020. Faculdade de Educação (FAED) Universidade Federal da Grande Dourados (UFGD) 


\section{MORIZONTES - REVISTA DE EDUCAÇÃO}

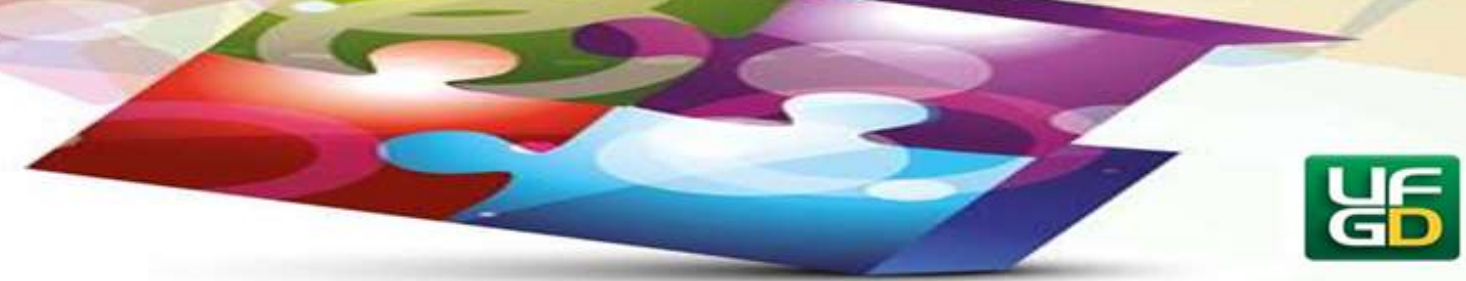

expressa, por exemplo, na preocupação com a avaliação do desempenho dos/as estudantes, medida por testes padronizados (PARENTE, 2017, p. 273).

Como salientado na parte introdutória deste artigo, Paro (1998, 1999), Oliveira (2008) e Di Giorgi et al. (2011) defendem o levantamento das necessidades formativas dos gestores/as por meio de um processo de diálogo contínuo com as instâncias e esferas dos sistemas de ensino, a fim de se estabelecer uma atuação profissional pautada nas dimensões social, cultural, política e econômica.

Também merece atenção, o fato de que embora a maioria, das diretoras, tenha mencionado não ter recebido formações a partir de suas necessidades. Quando questionadas a respeito do conteúdo e impacto das formações (Quadro 03), as participantes 1, 3, 4 e 6 argumentaram que, contribuíram muito no fazer da gestão e que nestes processos formativos houve aprendizagens importantes, a exemplo do contato com leis necessárias aos trâmites práticos da escola.

Quadro 03 - Impacto das formações recebidas pelas diretoras

\begin{tabular}{|c|c|}
\hline Participantes & Respostas \\
\hline Diretora 1 & $\begin{array}{l}\text { Contribuiu em como fazer a gestão, tudo que nós fazemos, em relação a tudo } \\
\text { que existe na escola, forma de direcionar a escola, tudo é focado para a } \\
\text { educação. Houve aprendizagem nos processos formativos recebidos, teve } \\
\text { muita aprendizagem, porque estamos sempre em aprendizagem [...] A } \\
\text { respeito dos cursos na área de gestão teve um curso longo, o Progestão, eu } \\
\text { ainda era professora e sobraram vagas, daí eu participei [...]. Foi um curso } \\
\text { que somou muito. }\end{array}$ \\
\hline Diretora 2 & Eu é que sempre vou à busca de formação, por conta própria. \\
\hline
\end{tabular}

JESUS, Josenildo de. DI GIORGI, Cristiano Amaral Garboggini. FRANCISCO, Marcos Vinicius. Políticas educacionais para formação continuada de diretoras escolares do município de Regente Feijó-SP Horizontes - Revista de Educação, Dourados-MS, v. 9, n. 41, 2020. Faculdade de Educação (FAED) Universidade Federal da Grande Dourados (UFGD) 


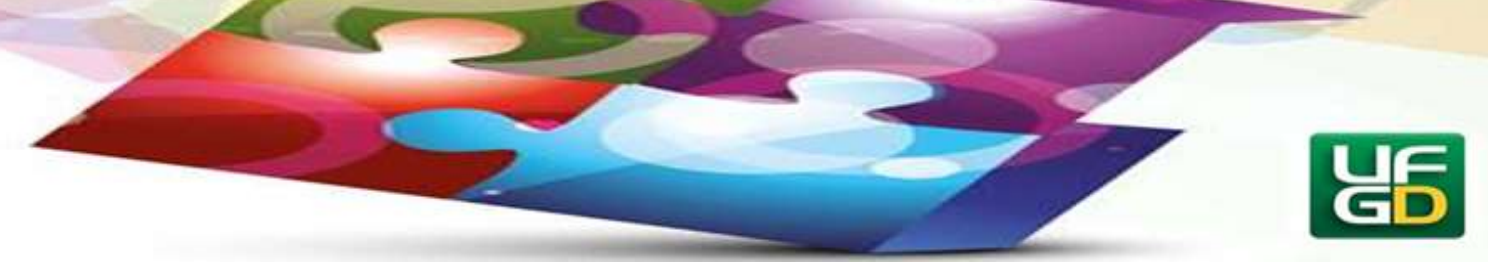

\begin{tabular}{|c|c|}
\hline Diretora 3 & $\begin{array}{l}\text { Foram muito importantes pra mim, porque a gente precisa estar à parte do } \\
\text { que está acontecendo, sabendo mais as coisas né, estudando melhor, eles } \\
\text { trazem sempre muitas leis, muitas coisa que a gente não está por dentro. } \\
\text { Então pra mim é muito importante o processo de informação. Destaco o } \\
\text { Progestão, utilizo muito do que vi ali. }\end{array}$ \\
\hline Diretora 4 & $\begin{array}{l}\text { Tudo que se aprende é importante, porém, ainda há muitas dificuldades, o } \\
\text { gestor precisa de formação, de esclarecimento, de formação para lidar com } \\
\text { pessoas. Olhar para o aluno, o diretor deve entender de relações humanas, de } \\
\text { leis, e minha autoridade tem limite. }\end{array}$ \\
\hline Diretora 5 & Eu vou atrás por conta própria, pois necessito de muitas coisas não ofertadas. \\
\hline Diretora 6 & $\begin{array}{l}\text { Ajudaram para que eu soubesse as funções de uma diretora. Participei até de } \\
\text { algumas formações dirigidas aos professores. Como disse foram muitos } \\
\text { cursos, mas o Progestão eu ainda consulto, pois tem muitas coisas que ainda } \\
\text { estou aprendendo, ainda tem os cursos e palestras oferecidas pela prefeitura } \\
\text { para gestores e a Secretaria de Educação está sempre à disposição para nos } \\
\text { atender. }\end{array}$ \\
\hline Diretora 7 & $\begin{array}{l}\text { Minha experiência é de sala de aula, e dos cursos que fiz como professora, } \\
\text { isso aí é que me ajudou a trabalhar, mas na área de gestão, gestão mesmo, } \\
\text { ainda não considero ter recebido. }\end{array}$ \\
\hline
\end{tabular}

Fonte: Pesquisa de Campo (2019-2020)

Sobre o Progestão ${ }^{4}$, mencionado na fala de algumas das diretoras, participantes da pesquisa, Barreiro e Moura (2010, p. 122) fazem algumas ponderações já que "a gestão democrática não deve ser entendida como um fim a ser atingido com o intuito de atender às diretrizes propostas pela legislação ou pelos programas de formação continuada, mas ser

\footnotetext{
4“Foi lançado em 05 de abril de 2001, pelo Conselho Nacional de Secretários de Educação (CONSED), o Programa de Capacitação a Distância para Gestores Escolares (Progestão), concebido como política inovadora no campo da formação continuada de dirigentes escolares das escolas públicas, organizado nas modalidades presencial e a distância (PROGESTÃO, 2004)” (BARREIRO; MOURA, 2010, p. 112).
}

JESUS, Josenildo de. DI GIORGI, Cristiano Amaral Garboggini. FRANCISCO, Marcos Vinicius. Políticas educacionais para formação continuada de diretoras escolares do município de Regente Feijó-SP Horizontes - Revista de Educação, Dourados-MS, v. 9, n. 41, 2020. Faculdade de Educação (FAED) Universidade Federal da Grande Dourados (UFGD) 


\section{MORIZONTES - REVISTA DE EDUCAÇÃOO}

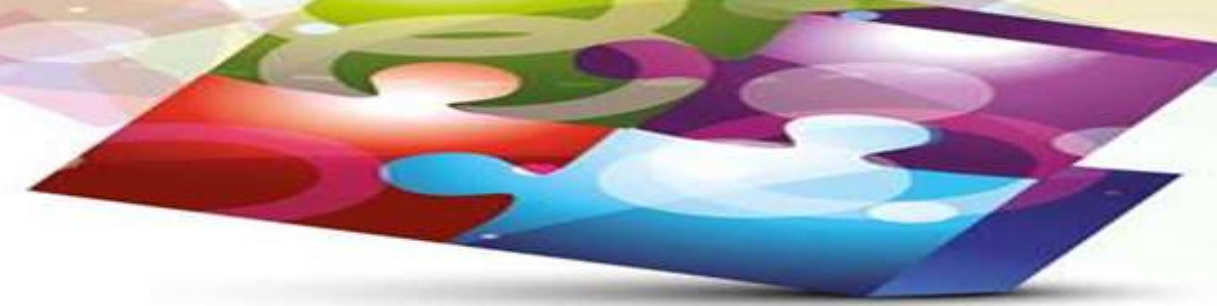

incorporada como prática social no cotidiano escolar". Tais ponderações são importantes, sobretudo porque costuma não haver um acompanhamento desses programas de formação continuada, acrescido ao fato de que "as atribuições administrativas de docentes e gestores que aumentam a cada dia. A rotina na escola e a descontinuidade das reflexões se incumbem do esquecimento das ações formativas” (BARREIRO; MOURA, 2010, p. 123)

E por mais que algumas das gestoras apresentem certo entusiasmo com as ações formativas recebidas, não se pode desconsiderar que diante das necessidades de transformação da educação escolar, bem como das “necessárias mudanças na estrutura de poder e gestão dessa instituição, encontram-se os profissionais [...] que constroem cotidianamente a escola, os quais estão imersos em teorias e práticas”, as quais necessitam ser identificadas e, posteriormente, analisadas, sobretudo se há a pretensão em “avançar na direção de uma compreensão crítica acerca da educação, com a intenção de superação do estado de precariedade educacional" vigente (VIOTTO FILHO; PONCE, 2015, p. 18).

\section{CONSIDERAÇÕES FINAIS}

Por meio desta pesquisa foi possível identificar que no município investigado, a formação continuada, de forma majoritária, ocorre apenas a partir das ações ofertadas pela Secretaria Municipal de Educação. As gestoras, em sua maioria, valorizam a formação contínua e destacaram a importância de terem participado dos processos oportunizados. Elas têm clareza de que a formação continuada é relevante para o seu trabalho.

Por outro lado, nota-se que a formação continuada oferecida é fragmentada e não leva em consideração as necessidades formativas das diretoras. Levando em conta estas conclusões,

JESUS, Josenildo de. DI GIORGI, Cristiano Amaral Garboggini. FRANCISCO, Marcos Vinicius. Políticas educacionais para formação continuada de diretoras escolares do município de Regente Feijó-SP Horizontes - Revista de Educação, Dourados-MS, v. 9, n. 41, 2020. 


\section{MORIZONTES - REVISTA DE EDUCAÇÃO}

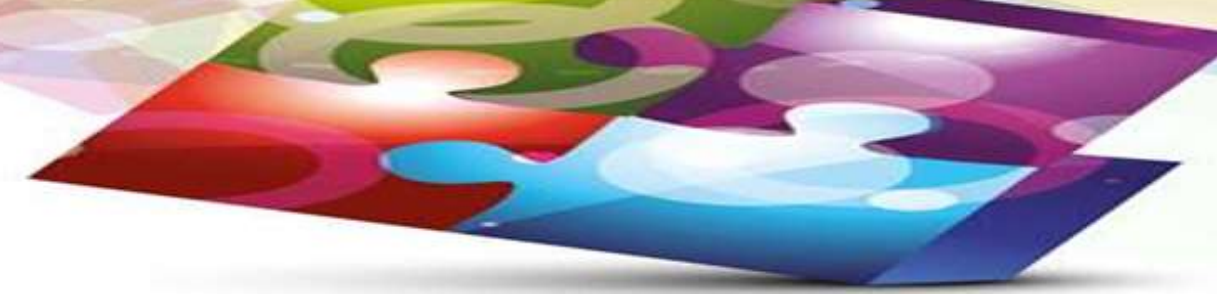

cabe ressaltar que a formação continuada de gestores/as é um tema que mereceria maior atenção na pesquisa educacional e, principalmente, no âmbito das políticas educacionais. Pois, se uma formação continuada de gestores feita de forma precária já é valorizada e tem um efeito nas percepções das diretoras, não há dúvidas de que uma formação alicerçada e estruturada a partir das necessidades formativas e do conhecimento científico, filosófico e artístico, seria possível obter um impacto muito significativo na melhoria das práticas de gestão escolar e, certamente, também, na melhoria da qualidade da educação escolar de uma forma geral.

\section{REFERÊNCIAS}

BACZINSKI, Alexandra Vanessa de Moura; COMAR, Sueli Ribeiro A educação brasileira: perspectivas para a formação omnilateral em tempos de capitalismo. Colloquium Humanarum, Presidente Prudente, v. 16, n. 2, p. 79-92, abr./jun. 2019. Disponível em: http://journal.unoeste.br/index.php/ch/article/view/3049. Acesso em: 05 nov. 2020.

BARREIRO, Iraíde Marques de Freitas; MOURA, Gabriella Garcia. Gestão democrática na escola: as impressões dos participantes do programa Progestão. Revista Eletrônica de Educação, São Carlos, UFSCar, v. 4, n. 2, p. 111-125, nov. 2010. Disponível em: https://repositorio.unesp.br/bitstream/handle/11449/127074/ISSN1982-7199-2010-04-02-111125.pdf? sequence=1. Acesso em: 14 mar. 2020.

CRUZETTA, Danieli D' Aguiar; SOUZA, Ângelo Ricardo de. As formas de escolha dos diretores das escolas de educação infantil nas redes municipais das capitais brasileiras. Revista @mbienteeducação, São Paulo, v. 13, n. 3, p. 138-154, set./dez 2020. Disponível em: http://publicacoes.unicid.edu.br/index.php/ambienteeducacao/article/viewFile/956/779.

Acesso em: 07 nov. 2020.

JESUS, Josenildo de. DI GIORGI, Cristiano Amaral Garboggini. FRANCISCO, Marcos Vinicius. Políticas educacionais para formação continuada de diretoras escolares do município de Regente Feijó-SP Horizontes - Revista de Educação, Dourados-MS, v. 9, n. 41, 2020. Faculdade de Educação (FAED) Universidade Federal da Grande Dourados (UFGD) 


\section{MORIZONTES - REVISTA DE EDUCAÇÃO}

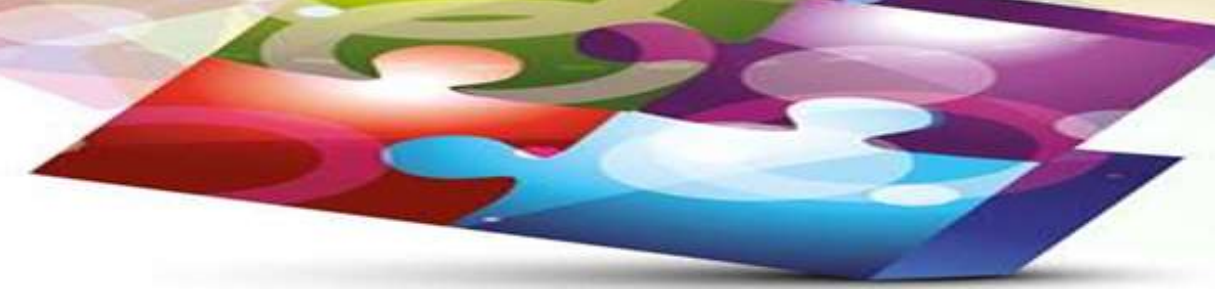

DI GIORGI, Cristiano Amaral Garboggini; MORELATTI, Maria Raquel Miotto; FÜRKOTTER, Monica; MENDONÇA, Naiara Costa Gomes de; LIMA, Vanda Moreira Machado; LEITE, Yoshie Ussami Ferrari . Necessidades formativas de professores de redes municipais: contribuições para formação de professores crítico-reflexivos. São Paulo: Cultura Acadêmica, 2011.

DUARTE, Newton; SAVIANI, Demerval. Entrevista com o professor Dermeval Saviani "Pedagogia Histórico-Crítica na atualidade". Colloquium Humanarum, Presidente Prudente, v. 16, n. 2, p. 4-12. Disponível em: http://journal.unoeste.br/index.php/ch/article/view/3121. Acesso em: 08 nov. 2020. https://doi.org/10.5747/ch.v16i2.3121

EVANGELISTA, Olinda; SHIROMA, Eneida Oto. Subsídios teórico-metodológicos para o trabalho com documentos de política educacional: contribuições do marxismo. In: CÊA, Georgia Sobreira; RUMMERT, Sonia Maria; GONÇALVES, Leonardo Dorneles (Orgs.). Trabalho e educação: interlocuções marxistas. Rio Grande: Editora da FURG, 2019. p. 83-120.

INSTITUTO BRASILEIRO DE GEOGRAFIA E ESTATÍSTICA. Regente Feijó. 2020. Disponível em: https://cidades.ibge.gov.br/brasil/sp/regente-feijo/panorama. Acesso em: 15 abr. 2020.

JESUS, Saul Neves de. Psicologia da educação. Coimbra: Quarteto, 2004.

LIBÂNEO, José Carlos. Didática. 2 ed. São Paulo: Cortez, 2013.

MARIN, Alda Junqueira. Educação continuada: introdução a uma análise de termos e concepções. Cadernos Cedes, Campinas, v. 36, p. 13-20, 1995.

OLIVEIRA, Maria Auxiliadora Monteiro. Gestão educacional: novos olhares, novas abordagens. São Paulo: Editora Vozes, 2008.

PAULO NETTO, José. Introdução ao estudo do método de Marx. São Paulo: Expressão Popular, 2011.

JESUS, Josenildo de. DI GIORGI, Cristiano Amaral Garboggini. FRANCISCO, Marcos Vinicius. Políticas educacionais para formação continuada de diretoras escolares do município de Regente Feijó-SP Horizontes - Revista de Educação, Dourados-MS, v. 9, n. 41, 2020. Faculdade de Educação (FAED) Universidade Federal da Grande Dourados (UFGD) 


\section{HORIZONTES - REVISTA DE EDUCAÇÃO}

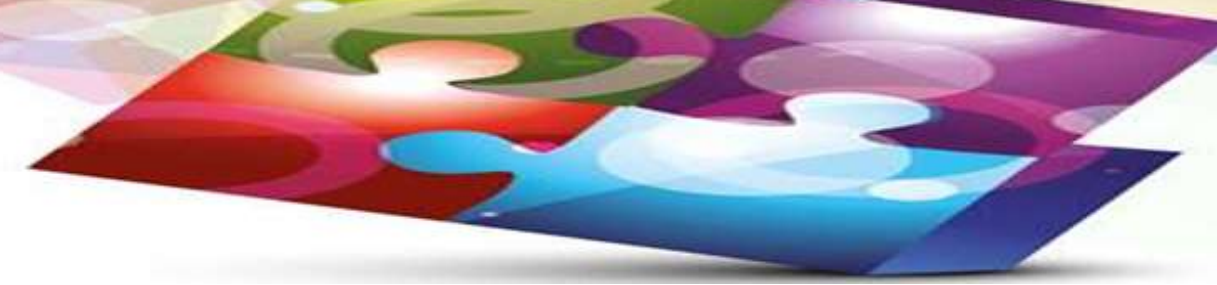

PARENTE, Juliano Mota. Gestão escolar no contexto gerencialista: o papel do diretor escolar.

Roteiro, Joaçaba, v. 42, n. 2, p. 259-280, maio./ago. 2017. Disponível em: https://portalperiodicos.unoesc.edu.br/roteiro/article/view/12535. Acesso em: 07 nov. 2020.

PARO, Vitor Henrique. Gestão democrática da escola pública. São Paulo: Ática, 1998.

PARO, Vitor Henrique. Administração escolar: introdução crítica. São Paulo: Cortez, 1999.

PARO, Vitor Henrique. A educação, a política e a administração: reflexões sobre a prática do diretor de escola. Educação e Pesquisa, São Paulo, v. 36, p. 763-778, 2010.

POLI, Luzenir; LAGARES, Rosilene. Dilemas da gestão democrática da educação frente ao contexto da Nova Gestão Pública. RBPAE, v. 33, n. 3, p. 835 - 849, set./dez. 2017.

VIOTTO FILHO, Irineu Aliprando Tuim; PONCE, Rosiane de Fátima. Psicologia e Pedagogia: uma relação crítica e dialética no interior da escola pública. In: VIOTTO FILHO, Irineu Aliprando Tuim; RODRIGUES, Silvia Adriana. Educação e formação humana: interlocuções críticas e dialéticas. Curitiba: CRV, 2015. p. 17-30.

JESUS, Josenildo de. DI GIORGI, Cristiano Amaral Garboggini. FRANCISCO, Marcos Vinicius. Políticas educacionais para formação continuada de diretoras escolares do município de Regente Feijó-SP Horizontes - Revista de Educação, Dourados-MS, v. 9, n. 41, 2020. Faculdade de Educação (FAED) Universidade Federal da Grande Dourados (UFGD) 